\title{
Formulation and Stability Studies of Fast Disintegrating Tablets of Amlodipine Besylate
}

\author{
Syed Furqan Ahsan', Muhammad Ali Sheraz ${ }^{1,2, \star}$, Marium Fatima Khan², Zubair Anwar ${ }^{3}$, Sofia Ahmed ${ }^{1}$, \\ lqbal Ahmad ${ }^{3}$
}

'Department of Pharmaceutics, Baqai Institute of Pharmaceutical Sciences, Baqai Medical University, Karachi, PAKISTAN. ${ }^{2}$ Department of Pharmacy Practice, Baqai Institute of Pharmaceutical Sciences, Baqai Medical University, Karachi, PAKISTAN. ${ }^{3}$ Department of Pharmaceutical Chemistry, Baqai Institute of Pharmaceutical Sciences, Baqai Medical University, Karachi, PAKISTAN.

\begin{abstract}
Introduction: Among tablets, fast dissolving technology has gained considerable popularity due to their rapid onset of action. Amlodipine besylate (ADB) is a longacting calcium channel blocker that is used in the treatment of angina and hypertension which are life-threatening conditions and require immediate relief. Currently, no fast dissolving tablet dosage form of ADB is commercially available. Methods: $A$ total of seven fast disintegrating tablets of Amlodipine besylate (ADB) have been prepared by direct compression method employing various excipients (Disintegrants and binders) in different concentrations. Pre-compression and post-compression studies were performed along with the storage in the stability chambers under real $\left(30 \pm 2{ }^{\circ} \mathrm{C} / 65 \pm 5 \% \mathrm{RH}\right)$ and accelerated conditions $\left(40 \pm 2{ }^{\circ} \mathrm{C} / 75 \pm 5 \% \mathrm{RH}\right)$ for six months. The assay of ADB was performed using a validated UV spectrometric method at $361 \mathrm{~nm}$. Results: The release of $A D B$ from tablets has been found to be very fast with almost more than $85 \%$ drug released within $15 \mathrm{~min}$. The release of drug from all the tablet formulations followed Higuchi model. Conclusion: The use of sodium bicarbonate as super disintegrant has greatly promoted the rapid release of the active drug. The binder has been shown to affect the tensile strength of the tablets. The stability studies for six months in aluminum blister packaging indicated no significant change in concentration in the majority of the formulations. This study provides basic groundwork related to the formulation of fast disintegrating tablets of ADB.
\end{abstract}

Key words: Amlodipine besylate, Direct compression, Drug release, Fast disintegrating tablets, Model dependent and independent methods, Pre-compression and postcompression studies.

\section{INTRODUCTION}

The tablet dosage form is one of the most popular and widely preferred drug delivery systems due to the advantages both to the manufacturer and the patient. ${ }^{1,2}$ Among the different types of tablets available, fast dissolving technology has gained considerable popularity for the last two decades due to its ability to release the drug much quicker than the conventional drug delivery systems. ${ }^{3,4}$ Fast disintegrating tablets, also called as core immediate-release tablets, are employed for a quicker response or therapeutic effect at the site of action. They can be prepared by different techniques such as direct compression, ${ }^{4,5}$ lyophilization or sublimation, ${ }^{6,7}$ effervescent method $^{8}$ and direct molding method., ${ }^{910}$

Amlodipine (AD) is a dihydropyridine calcium channel blocker, which is used alone or in combination with other medicines for the treatment of chronic stable angina, certain types of vasospastic angina and in the management of mild to moderate essential hypertension. ${ }^{11,12}$ More prolonged half-life, high volume of distribution and gradual elimination highlight $\mathrm{AD}$ from other agents of this class. Amlodipine besylate (ADB) is a sparingly soluble orally administered drug
Submission Date: 13-10-2018; Revision Date: 28-12-2018; Accepted Date: 22-04-2019

DOI: 10.5530/ijper.53.3.80 Correspondence: Dr. Muhammad Ali Sheraz, Baqai Institute of Pharmaceutical Sciences, Baqai Medical University, 51, Deh Tor, Gadap Road, Super Highway, Karachi, PAKISTAN.

Phone: +92 21344102938

E-mail: ali_sheraz80@

hotmail.com

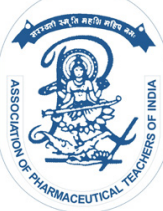

www.ijper.org 
with slow absorption as the rate of absorption is often controlled by the rate of dissolution. ${ }^{4,11,13,14}$ Various salts of AD have been prepared, e.g. besylate, mesylate, maleate, etc. However, whichever salt is used, the strength of the dosage form is always determined with respect to AD. ${ }^{12}$ Among all the salts available, the most commonly employed form is besylate, which is known to have better solubility than AD alone. ${ }^{15,16}$

Various strategies have been employed to increase the bioavailability of $\mathrm{AD}$ which includes the development of new formulations, use of different excipients and formulation techniques, etc. ${ }^{17}$ Presently, no fast disintegrating tablet dosage form of $\mathrm{AD}$ is available in the market. The object of the present work is to develop fast disintegrating tablets of $\mathrm{ADB}$ that will increase the rate of dissolution of $\mathrm{AD}$ after oral administration. This study would help in improving the release characteristics and bioavailability of the drug. The study would involve the use of various disintegrants along with other excipients for the formulation of fast disintegrating tablets to achieve rapid disintegration and release. A number of parameters including compatibility, disintegration, dissolution, bulk and tap density, etc. would be studied to examine the appropriateness of the formulated tablets. The stability studies of the prepared dosage form would be carried out according to the guideline of the International Council for Harmonization (ICH).${ }^{18}$ This study would help the pharmaceutical scientists in the development of a stable and effective dosage form that could be used in emergency conditions like angina pectoris for rapid therapeutic effect.

\section{MATERIALS AND METHODS}

\section{Materials}

ADB (99\%) was procured from Amsal Chem Pvt. Ltd. (India). Microcrystalline cellulose (Avicel PH-102) from JRS Pharma (Germany), dibasic calcium phosphate anhydrous $\left(\mathrm{CaHPO}_{4}\right)$ from Reephos Chemicals, (China), povidone $\mathrm{K}-30\left(\mathrm{M}_{\mathrm{r}} 40,000-80,000\right)$ from Ash Land Pvt. Ltd. (USA), sodium bicarbonate $\left(\mathrm{NaHCO}_{3}\right)$ from Tata Chemicals Ltd. (India), sodium starch glycolate from Yung Zip Chemical Industries Company Ltd. (Taiwan) and magnesium stearate from Peter Greven $\mathrm{GmbH}$ and Co. KG (Germany). Freshly boiled glassdistilled water was used throughout the work. All other solvents and reagents used in the study were of analytical grade obtained from BDH / Merck.

\section{Formulation of Fast Disintegrating Tablets of Amlodipine Besylate}

On the basis of various $\mathrm{ADB}$ formulations reported in the literature, ${ }^{4,19-23}$ a general formula for the formula- tion of fast disintegrating tablets was developed, which is presented in Table 1. In order to evaluate the effect of various formulation ingredients on the physico-chemical properties of the fast disintegrating tablets, six other formulations of $\mathrm{ADB}$ were prepared with varying concentration of the disintegrants and binder (Table 2). The concentration of each excipient was selected according to the ranges provided in the Handbook of Pharmaceutical Excipients ${ }^{24}$ and IIG (Inactive Ingredients) Limit of Food and Drug Administration. ${ }^{25}$

\section{Confirmation of the Purity}

The pure powdered samples of the drug and excipients were subjected to FTIR spectrometry for the determination of their purity. Before analysis, each sample was thoroughly ground and mixed in a mortar and pestle for 5 min. The spectra were collected using an FTIR spectrometer (Spectrum One, Perkin Elmer, USA) through Universal Attenuated Total Reflection (UATR) diamond crystal sampling assembly. Each spectrum was collected in a range of $4000-650 \mathrm{~cm}^{-1}$ by performing 64 scans with a $4 \mathrm{~cm}^{-1}$ resolution and analyzed using the built-in Spectrum One software (version 6.2.0).

\section{Formulation of Tablets by Direct Compression Technique}

All the ingredients were passed separately through a sieve of mesh size 40 via an oscillator. The sieved drug and sodium bicarbonate were mixed together for $5 \mathrm{~min}$ in a bin blender (Thuf Engineering KIA, Karachi, Pakistan). Subsequently, all other excipients were added to this mixture one by one with a mixing time of $5 \mathrm{~min}$ each. The tablets of $200 \mathrm{mg}( \pm 3 \%)$ weight were prepared by direct compression using a compression machine (D type 16-station D3B, Manesty, England) at a speed of $12 \mathrm{rpm}$.

\section{Packaging}

All formulations were packed in Alu-Alu (Aluminum) blisters (Chinese Blister Machine, Taiwan). Each blister was placed in a secondary container which was a plain carton containing the formulation information.

\section{Leakers Test}

Randomly two consecutive cuts from the blister machine in doublet for each formulation were selected and subjected to leakage test (Model LT-101P, Electro $\mathrm{Lab}$, India). The blisters were placed in the instrument containing $0.5 \%$ methylene blue solution as indicator. The perforated polypropylene discs were placed over the sample to avoid floating. The vacuum pressure was set at $200 \mathrm{~mm} \mathrm{Hg}$ with a holding time of $1 \mathrm{~min}$. The blisters were taken out and dried with a lint-free cloth. 
The leakage of the blisters was checked visually by opening the samples and observing the color of the dye inside the blister.

\section{Pre-Compression Studies}

The blended mixture of powders was evaluated for various parameters such as.

\section{Bulk and Tapped Density}

A pre-weighed $100 \mathrm{ml}$ empty cylinder was filled with the blended powder (i.e. ADB + excipients) up to the highest mark. The cylinder was weighed again without tapping. The cylinder was then manually tapped on a smooth surface 100 times from a height of $10 \mathrm{~cm}$ with a $2 \mathrm{~s}$ interval. It was weighed repeatedly after every 25 taps and the volume occupied was recorded. The procedure was repeated thrice for every formulation and the mean result was calculated. The bulk and tapped densities of the blended powders were calculated by using the following formulae: ${ }^{26}$

\begin{tabular}{|l|l|}
\hline \multirow{2}{*}{ Bulk density $=$} & $\mathrm{W}_{2}-\mathrm{W}_{1}$ \\
\cline { 2 - 2 } & $\mathrm{V}_{1}$ \\
\hline \multirow{2}{*}{ Tapped density $=$} & $\mathrm{W}_{2}-\mathrm{W}_{1}$ \\
\cline { 2 - 2 } & $\mathrm{V}_{2}$ \\
\hline
\end{tabular}

$\mathrm{W}_{1}$ is the weight of the empty cylinder;

$\mathrm{W}_{2}$ is the total weight (cylinder + powder);

$\mathrm{V}_{1}$ is the total volume of the powder (untapped);

$\mathrm{V}_{2}$ is the total volume of the powder (tapped).

\section{Carr's Index or Compressibility Index}

The $\%$ compressibility of the powdered material was calculated as follows: ${ }^{26}$

\begin{tabular}{|l|l|l|}
\hline \multirow{2}{*}{$\mathrm{C}=$} & Tapped density - Bulk density & \multirow{2}{*}{$\times 100$} \\
\cline { 2 - 3 } & Tapped density & \\
\hline
\end{tabular}

\section{Hausner Ratio}

Hausner Ratio (HR) was calculated by the following formula: ${ }^{26}$

$$
\begin{array}{|l|l|}
\hline \mathrm{HR}= & \text { Tapped density } \\
\cline { 2 - 2 } & \text { Bulk density } \\
\hline
\end{array}
$$

\section{Angle of Repose}

The blended powder was passed through a funnel that was attached vertically to a stand until a maximum cone height $(\mathrm{H})$ was obtained. The diameter of the heap (D) was measured and angle of repose $(\theta)$ was calculated by the following formula: ${ }^{26}$ \begin{tabular}{|l|l|}
\hline $\tan (\alpha)=$ & Height \\
\cline { 2 - 2 } & 0.5 Base \\
\hline
\end{tabular}

\section{Post-Compression Studies}

The core tablets were evaluated for various quality control tests which are described as follows.

\section{Organoleptic Studies}

All formulations were evaluated for their organoleptic properties throughout the study including appearance (color, shape and size) and odor.

\section{Weight Variation}

A total of 20 tablets were selected randomly from each formulation and average weight was determined. Each tablet was then weighed individually and compared with the average weight and the deviation was calculated. ${ }^{26}$

\section{Thickness and Breaking Force of the Tablets}

The thickness and breaking force of the tablets were measured using a digital hardness testing instrument (PTB 111EP, Pharma Test, Germany). Thickness was measured in $\mathrm{mm}$ while breaking force was recorded in kilo poise unit.

\section{Friability}

The friability of the core tablets from each formulation was measured using an automated Friabilator (EF-2, ElectroLab, India) according to the method described in British Pharmacopoeia. ${ }^{26}$ Since the weight of each tablet is $200 \mathrm{mg}$, therefore, a number of tablets equivalent to $6.5 \mathrm{~g}$ (i.e. $\sim 33$ tablets) were placed in the plastic chamber of the instrument. The chamber was rotated at a speed of $25 \pm 1 \mathrm{rpm}$ for 4 min. (i.e. 100 rotations) and the tablets were dropped from a height of 6 inches on each rotation. The friability of each formulation was determined in triplicate and calculated using the following formula:

\begin{tabular}{|l|l|l|}
\hline $\mathrm{F}=$ & Initial Weight - Final Weight & $\times 100$ \\
\cline { 2 - 3 } & Initial Weight & \\
\hline
\end{tabular}

\section{Disintegration Test}

The disintegration time for all tablets was determined according to the method described in British Pharmacopoeia. ${ }^{26}$ A total of 6 tablets were placed individually in each tube of the disintegration apparatus (PTZ-S, Pharma Test, Germany) and the discs were placed over the tablets to avoid floating. The disintegration medium was distilled water maintained at a temperature of $37 \pm 2^{\circ} \mathrm{C}$. The instrument was run until no solid mass was observed in any tube and the time was noted. The 
disintegration time of each formulation was determined in triplicate.

\section{Drug Assay}

The assay was performed spectrometrically according to the method of Dahima et al. ${ }^{27}$ and Ghenge et al. ${ }^{22}$ Due to change in assay wavelength and use of different formulation ingredients, the method was validated prior to its application according to the guideline of $\mathrm{ICH} .{ }^{18}$

A total of 20 pre-weighed tablets from each formulation were powdered in a mortar with the help of a pestle and an amount equivalent to $10 \mathrm{mg}$ was weighed accurately. The weighed powder was dissolved in $100 \mathrm{ml}$ of methanol. From this stock, $1 \mathrm{ml}$ was taken and further diluted to $10 \mathrm{ml}$ with methanol. The solution was filtered using Whatman No. 40 filter paper (Schleicher and Schuell, $\mathrm{UK})$. The first few $\mathrm{ml}$ of the filtrate were discarded and the remaining were collected in a screw cap tube and closed tightly to prevent evaporation of the solvent. The drug content was analyzed spectrometrically (UV1601, Shimadzu, Japan) at $361 \mathrm{~nm}$ using quartz cells of $10 \mathrm{~mm}$ path length and the concentration was calculated using the following formula:

\begin{tabular}{|c|c|c|c|}
\hline \multirow{2}{*}{ Concentration $=$} & \multicolumn{3}{|c|}{ Absorbance $\times$ dilution factor } \\
\hline & \multicolumn{3}{|c|}{$\mathrm{A}(1 \%, 1 \mathrm{~cm}) \times 1 \mathrm{~cm}$} \\
\hline$\%$ Recovery $=$ & Concentration found & $x$ & 100 \\
\hline 70 Recovery & Concentration added & 사 & 100 \\
\hline
\end{tabular}

\section{Content Uniformity}

A total of 10 tablets from each formulation were selected randomly. Each tablet was powdered finely in a mortar with pestle and an amount equivalent to $10 \mathrm{mg}$ was taken and assayed as described above.

\section{Dissolution Studies}

The release rate of ADB from each formulation was determined by 7 vessels dissolution testing apparatus II (Paddle method) (PT-DT70, Pharma Test, Germany). The dissolution test was performed using $900 \mathrm{ml}$ of $0.01 \mathrm{~N} \mathrm{HCl}(\mathrm{pH} 2.0)$ at $37 \pm 0.5^{\circ} \mathrm{C}$. The Teflon paddles were rotated at a speed of $50 \mathrm{rpm}$ for $15 \mathrm{~min}$. A $5 \mathrm{ml}$ sample of the solution was withdrawn after every $3 \mathrm{~min}$ interval and an equivalent amount of the dissolution medium was added to maintain the sink conditions. The samples were filtered through $0.45 \mu$ membrane filter (Micropore, USA), the absorbance was measured at 361 $\mathrm{nm}$ and the drug content was determined as described in the assay section. The dissolution profiles of the test formulations were compared with the conventional tablets of $\mathrm{ADB}$ purchased from the local pharmacy.

\section{Model-Dependent Method}

The dissolution profiles of different formulations of the same drug are described by the model dependent methods which are based on different mathematical calculations. ${ }^{28-31}$ In order to evaluate the appropriate drug release kinetic model illustrating the dissolution profile of the formulations, different model dependent methods have been used and are as follows:

$$
\begin{aligned}
& \text { Zero-order: } \quad \mathrm{C}_{0}-\mathrm{C}_{t}=k_{0} t \\
& \text { First-order: } \quad \ln \left(\mathrm{C}_{0} / \mathrm{C}_{t}\right)=k t \\
& \text { Higuchi: } \quad \mathrm{C}_{t}=k_{\mathrm{H}} t^{1 / 2} \\
& \text { Hixson-Crowell: } \mathrm{C}_{0}^{1 / 3}-\mathrm{C}_{t}^{1 / 3}=k t \\
& \text { Korsmeyer-Peppas: } \quad \mathrm{C}_{t} / \mathrm{C}_{0}=k t^{\mathrm{n}} \\
& \text { where } \mathrm{C}_{0}=\text { initial concentration; } \\
& \mathrm{C}_{t}=\text { concentration at time } t \\
& k_{\mathrm{H}}=\text { Higuchi dissolution constant; } \\
& k=\text { release rate constant; } \\
& n=\text { slope. }
\end{aligned}
$$

\section{Model-Independent Method}

The dissolution similarities have been evaluated by calculating similarity factor, $f_{2}$, at different time intervals using the following equation: ${ }^{32,33}$

\begin{tabular}{|l|l|}
\hline$f_{2}=$ & $50 \times \log \left\{\left[1+(1 / \mathrm{n}) \Sigma_{\mathrm{t}=1}{ }^{\mathrm{n}}\left(\mathrm{R}_{\mathrm{t}} \mathrm{T}_{\mathrm{t}}\right)^{2}\right]^{-0.5} \times 100\right\}$ \\
\hline
\end{tabular}

where $n=$ The number of time intervals;

$\mathrm{R}=$ The dissolution value of the standard at time $t$; $\mathrm{T}=$ The dissolution value of the test at time $t$.

\section{Stability Studies}

All blister packed tablet formulations of $\mathrm{ADB}$ were stored in a stability chamber at $30 \pm 2^{\circ} \mathrm{C} / 65 \pm 5 \% \mathrm{RH}$ (Model YWER-A1001P, Dongguan Yuanyao Electronics Technology Co., Ltd., China) and $40 \pm 2{ }^{\circ} \mathrm{C} / 75 \pm 5 \%$ RH (Model NEC 2530RS, Newtronic Lifecare Equipment Pvt. Ltd., India) for six months. Each formulation was assayed at $0,1,2,3,4,5$ and 6 months of storage in triplicate.

\section{RESULTS AND DISCUSSION}

Confirmation of the Purity of Amlodipine Besylate and Excipients

The purity of $\mathrm{ADB}$ and excipients was confirmed by FTIR spectrometry. The spectra of pure drug and excipients are reported in the supplementary file (S- Figures 1-7). All spectra of the pure compounds were found identical to the reference standards indicating that the chemicals were of the highest purity. 


\section{Formulation of the Tablets}

Fast disintegrating tablets of ADB have been prepared by direct compression method (Table 2). The concentration of $\mathrm{ADB}$ has been kept constant in each formulation i.e. $13.86 \mathrm{mg}$, which is equivalent to $10 \mathrm{mg}$ of $\mathrm{AD}$ while varying concentrations of the binder and disintegrants have been used (Table 2). Each ingredient was selected on the basis of its suitability in the formulation. The formulations have been studied for various pre-compression and post-compression parameters that are discussed in the following sections.

\section{Pre-Compression Studies}

\section{Flow and Compressibility Properties}

Flowability of any powder is important for producing a uniform blend and consistent dosage forms having similar masses. ${ }^{34,35}$ Physical properties of the powder are found to have more impact on its flowability as compared to chemical properties. A total of seven fast disintegrating tablets have been formulated. The flow and the compression ability of the powder mixtures have been analyzed by determining the angle of repose, tapped and bulk density, Carr's index and Hausner's ratio and are reported as follows:

\section{Angle of Repose}

Although the angle of repose $(\theta)$ is not a direct measure of powder flowability still it is used widely. Powders having $\theta$ values of greater than $50^{\circ} \mathrm{C}$ are considered to have unsatisfactory flow whereas a value near to $25^{\circ} \mathrm{C}$ makes them good free-flowing material. ${ }^{35}$ In this study, all formulations showed an average $\theta$ of around $37^{\circ} \mathrm{C}$ indicating a moderate flow pattern of blended powders in all the formulations (Table 3).

\section{Tapped and Bulk Density}

Tapped and bulk densities are not only required to determine powder compressibility but they are also important in the overall tableting process as they are related to the correct mechanical strength, porosity and dissolution characteristics. ${ }^{34,35}$ The tapped and bulk densities of all the formulations have been found to be close to each other indicating good flow and compression properties (Table 3).

\section{Carr's or Compressibility Index}

The simplest way of measurement of the compressibility of a blend of different excipients and drug is through Carr's or compressibility index, which is an indication of the ease with which a material can be compressed. ${ }^{4,36}$ The values of compressibility index are reported in Table 3 that indicate average flow behavior

\begin{tabular}{|c|c|}
\hline Ingredients & Percentage $(w / w)$ \\
\hline $\begin{array}{c}\text { Active Pharmaceutical Ingredient } \\
\text { Amlodipine besylate }\end{array}$ & $6.93^{a}$ \\
\hline $\begin{array}{l}\text { Diluents } \\
\qquad \begin{array}{l}\text { Microcrystalline cellulose } \\
\text { Dibasic calcium phosphate }\end{array} \\
\text { anhydrous }\end{array}$ & $\begin{array}{l}59.57 \\
22.50\end{array}$ \\
\hline $\begin{array}{l}\text { Disintegrants } \\
\text { Sodium bicarbonate } \\
\text { Sodium starch glycolate }\end{array}$ & $\begin{array}{l}5.0 \\
3.0\end{array}$ \\
\hline Binder Po & 2.0 \\
\hline $\begin{array}{l}\text { Lubricant } \\
\qquad \text { Magnesium stearate }\end{array}$ & 1.0 \\
\hline
\end{tabular}

${ }^{a}$ Equivalent to $5 \%$ of $\mathrm{AD}$.

\begin{tabular}{|c|c|c|c|c|c|c|c|}
\hline \multirow{2}{*}{ Ingredients } & \multicolumn{7}{|c|}{ mg per tablet } \\
\hline & Standard & $F 1^{a}$ & $\mathrm{~F}^{\mathrm{a}}$ & $\mathbf{F}^{\mathbf{a}}$ & $\mathrm{F}^{\mathrm{a}}$ & F5 $^{\mathrm{a}}$ & $\mathrm{FG}^{\mathrm{a}}$ \\
\hline Amlodipine besylate $^{b}$ & 13.86 & 13.86 & 13.86 & 13.86 & 13.86 & 13.86 & 13.86 \\
\hline Microcrystalline cellulose ${ }^{c}$ & 119.14 & 121.14 & 117.14 & 121.14 & 117.14 & 123.14 & 115.14 \\
\hline Dibasic calcium phosphate & 45 & 45 & 45 & 45 & 45 & 45 & 45 \\
\hline Sodium bicarbonate & 10 & 10 & 10 & 10 & 10 & 6 & 14 \\
\hline Sodium starch glycolate & 6 & 4 & 8 & 6 & 6 & 6 & 6 \\
\hline Povidone K-30 & 4 & 4 & 4 & 2 & 6 & 4 & 4 \\
\hline Magnesium stearate & 2 & 2 & 2 & 2 & 2 & 2 & 2 \\
\hline Total weight ${ }^{c}$ & 200 & 200 & 200 & 200 & 200 & 200 & 200 \\
\hline
\end{tabular}

${ }^{\mathrm{a}} \mathrm{F}=$ Formulation.

${ }^{b} 13.86 \mathrm{mg}$ of $A D B$ is equivalent to $10 \mathrm{mg} A D$.

'The total weight of each formulation was adjusted by the change in the concentration of microcrystalline cellulose. 
Table 3: The pre-compression parameters for the powder blends of various formulations of ADB.

\begin{tabular}{|c|c|c|c|c|c|c|c|}
\hline \multirow{2}{*}{ Parameters } & \multicolumn{7}{|c|}{ Formulations } \\
\cline { 2 - 8 } & Standard & F1 & F2 & F3 & F4 & F5 & F6 \\
\hline Angle of repose $(\theta)$ & $37.14^{\circ}$ & $37.14^{\circ}$ & $38.23^{\circ}$ & $36.02^{\circ}$ & $37.14^{\circ}$ & $36.38^{\circ}$ & $36.86^{\circ}$ \\
\hline Bulk density $(\mathrm{g} / \mathrm{ml})$ & 0.4782 & 0.4456 & 0.4566 & 0.4621 & 0.4535 & 0.4580 & 0.4581 \\
\hline $\begin{array}{c}\text { Tapped density }(\mathrm{g} / \mathrm{ml}) \\
\text { Compressibility index } \\
(\%)\end{array}$ & 0.6550 & 0.6365 & 0.6254 & 0.6508 & 0.6298 & 0.6366 & 0.6190 \\
\hline $\begin{array}{c}\text { Hausner's ratio } \\
\text { Honyyyyyy}\end{array}$ & 1.36 & 1.42 & 1.36 & 1.40 & 1.38 & 1.39 & 25.99 \\
\hline
\end{tabular}

\begin{tabular}{|c|c|c|c|c|c|c|c|}
\hline \multicolumn{7}{|c|}{ Table 4: The post-compression parameters of all tablet formulations of ADB. } \\
\hline \multirow{2}{*}{ Parameters } & \multicolumn{7}{|c|}{ Formulations } \\
\cline { 2 - 8 } & Standard & F1 & F2 & F3 & F4 & F5 & F6 \\
\hline Thickness (mm) & $3.58-3.61$ & $3.61-3.63$ & $3.62-3.65$ & $3.56-3.61$ & $3.59-3.62$ & $3.58-3.63$ & $3.60-3.63$ \\
\hline Weight variation (mg) & $197-202$ & $195-202$ & $195-203$ & $197-206$ & $195-205$ & $196-204$ & $195-203$ \\
\hline Breaking force (Kp) & $10.6-12.2$ & $13.4-14.3$ & $10.9-11.3$ & $13.7-14.8$ & $14.5-15.4$ & $14.1-15.1$ & $10.4-10.9$ \\
\hline Friability (\%) & 0.05 & 0.03 & 0.04 & 0.07 & 0.02 & 0.06 & 0.09 \\
\hline Disintegration time (s) & 13 & 12 & 13 & 13 & 12 & 18 & 10 \\
\hline $\begin{array}{c}\text { Content uniformity } \\
(\%)\end{array}$ & $94-99$ & $92-101$ & $94-105$ & $96-109$ & $95-104$ & $91-100$ & $91-106$ \\
\hline
\end{tabular}

of the blends, which has been found adequate for the formulation of uniform dosage units.

\section{Hausner's Ratio}

Another important parameter used to determine powder compressibility and flowability is the Hausner ratio. A ratio of greater than 1.6 indicates cohesive and less free-flowing powders whereas values less than 1.6 or around 1.2 points towards more free-flowing powders. ${ }^{35}$ In this study, the ratios for all formulations have been found in the range of 1.35-1.42 indicating good flow and compression properties of the powder blends (Table 3).

\section{Post-Compression Studies}

\section{Organoleptic Studies}

The fast disintegrating tablets of $\mathrm{ADB}$ have been evaluated for their organoleptic properties such as color, shape, size and odor either alone or in comparison with each other. Organoleptic studies are considered important for identification, stability and consumer acceptance. ${ }^{37}$ All formulations appeared white in color with oval shape, plain from both sides and odorless indicating uniformity in all batches. A shade card was used to visually identify any color variations. No change in color as well as in appearance has been observed for any formulation at the time of tableting as well as during storage. Similarly, no odor has been sensed for any formulation throughout the course of the study.

\section{Weight Variation of the Tablets}

The weight of the tablets determines that a tablet is being made with the proper amount of drug. ${ }^{37}$ All core tablets must comply in weight with the tolerance limit given in the official compendia. In this study all fast disintegrating tablets of $\mathrm{ADB}$ have been prepared with a total weight of $200 \mathrm{mg}$ (Table 2). According to British Pharmacopoeia ${ }^{26}$ and the United States Pharmacopeia ${ }^{38}$ the variation allowed for tablets of such weight is $\pm 7.5 \%$. The average percent variation found in the tablets of each formulation is within $\pm 3 \%$ indicating good flowability of the powdered blends from the hopper to dies (Table 4).

\section{Thickness of the Tablets}

The consistent thickness of the tablets within the same or different batches is an indication of adequate blending with uniform tooling during the compression process. Moreover, the thickness is an important quality control test for tablet packaging as very thick tablets 


\begin{tabular}{l} 
Table 5: Validation data for the analysis of ADB by \\
UV spectrometric methoda. \\
Parameter \\
\multicolumn{1}{c|}{$\lambda_{\text {max }}$}
\end{tabular}

affect packaging either in blister or plastic containers. ${ }^{37}$ Generally, tablets are required to be kept within a variation of $\pm 5 \%{ }^{37}$ All formulations in this study showed identical thickness with values in the range of 3.56-3.65 $\mathrm{mm}$, indicating consistent manufacturing process (Table 4).

\section{Tablet Breaking Force and Friability}

The mechanical integrity of a tablet to withstand mechanical shocks of handling during manufacture, packaging and shipping can be determined by its breaking force/hardness and through friability test. ${ }^{37,38}$ The strength of a tablet plays a vital role in its dissolution and bioavailability as well as in marketing. ${ }^{37,39}$ The highest tablet breaking force of $15.4 \mathrm{Kp}$ has been found in tablets formulated with an increased amount of the binder (Povidone K-30), i.e. formulation 4 (Table 4). On the contrary, the lowest tablet breaking force has been observed in formulation 6, i.e. 10.4 (Table 4). It is interesting to note that the amount of povidone is minimum in formulation 3 but still the lowest breaking force has been observed in formulation 6 . This could be due to the presence of a high amount of sodium bicarbonate and low amount of microcrystalline cellulose in addition to povidone as compared to formulation 4 (Table 2). Microcrystalline cellulose is also known to have binder properties $^{24}$ whereas sodium bicarbonate is a super disintegrant and is known to affect tablet compaction. ${ }^{40}$

Along with the breaking force, it is important that a core tablet must possess a certain amount of resistance to friability in order to withstand mechanical stresses to chipping and surface abrasion. ${ }^{37,38}$ Similar results to that of tablet breaking force have been noted in the friability test. All formulations showed a friability of less than $0.1 \%$ indicating the excellent resistance of the formulations to mechanical stresses (Table 4). The highest friability has been observed in tablets of formulation 6 while the lowest in formulation 4 (Table 4).

\section{Disintegration Test}

The disintegration of tablets is an important parameter to ensure lot-to-lot uniformity. ${ }^{37}$ It is used as a quality assurance tool to confirm complete disintegration of solid oral dosage forms within the recommended time period when placed in a liquid medium under the investigational conditions as described in the particular official monographs. ${ }^{26,38}$

Magnesium stearate is known to cause a delay in tablet disintegration. ${ }^{24}$ Therefore, it was used in an equal concentration in all the formulations to nullify any hindrance in the disintegration of the tablets. All tablets of ADB have been found to disintegrate within 20 secs indicating towards the rapid availability of the active drug for absorption (Table 4). Formulation 6 has been found to be the quickest of all showing a disintegration time of only 10 secs, which is due to the presence of highest amount of super disintegrant i.e. $14 \mathrm{mg}$ of sodium bicarbonate (Table 2).

\section{Validation of the assay method}

The assay of pure ADB and its fast disintegrating tablets has been performed spectrometrically at a wavelength of $361 \mathrm{~nm}$. The method has been validated according to the guideline of ICH18 and the data are reported in Table 5. The calibration curve and overlay spectra of $\mathrm{ADB}$ are reported in Figure 1. The active drug has been calculated with reference to the parent molecule i.e. $13.86 \mathrm{mg}$ of $\mathrm{ADB}$ is equivalent to $10 \mathrm{mg}$ of $\mathrm{AD}$. The method has been found to be accurate and precise for the assay of ADB either alone (Table 5) or in tablet dosage form (Table 6). None of the excipients have been found to interfere with $\mathrm{ADB}$ at the assay wavelength of $361 \mathrm{~nm}$ indicating the selectivity of the assay method for the active drug. A typical UV of spectrum of fast 


\begin{tabular}{|c|c|c|c|c|c|c|}
\hline Formulation & $\begin{array}{c}\text { Amount } \\
\text { labeled (mg) }\end{array}$ & $\begin{array}{l}\text { Amount } \\
\text { found } \\
(\mathrm{mg})^{\mathrm{a}, \mathrm{b}}\end{array}$ & $\begin{array}{c}\text { Recovery } \\
(\%)^{\mathrm{a}, \mathrm{b}}\end{array}$ & $\begin{array}{c}\text { Mean recovery } \\
(\%) \pm \text { SD }\end{array}$ & $\begin{array}{c}\text { Relative } \\
\text { accuracy error } \\
(\%)^{c}\end{array}$ & RSD (\%) \\
\hline Standard & 10 & 9.81 & 98.14 & \multirow{7}{*}{$99.35 \pm 0.637$} & -1.21 & \multirow{7}{*}{0.641} \\
\hline 1 & 10 & 9.97 & 99.69 & & +0.34 & \\
\hline 2 & 10 & 9.92 & 99.16 & & -0.19 & \\
\hline 3 & 10 & 9.98 & 99.80 & & +0.45 & \\
\hline 4 & 10 & 9.90 & 98.99 & & -0.36 & \\
\hline 5 & 10 & 9.99 & 99.89 & & +0.54 & \\
\hline 6 & 10 & 9.98 & 99.81 & & +0.46 & \\
\hline
\end{tabular}

disintegrating tablets of $\mathrm{ADB}$ is shown in dotted line in Figure 1b.

\section{Content Uniformity}

Uniformity of content in each unit is one of the most concerned requirements of a tablet dosage form. All quality control parameters would be considered void if the tablet-to-tablet distribution of the drug substance is not uniform. The uniformity of the dosage units largely depends on the formulation process. Therefore, process design needs to be implemented in a manner that must provide correct potency and little content variability. Weight variation test is considered acceptable if the drug is present in an amount excess of $25 \mathrm{mg} .{ }^{38} \mathrm{In}$ this study, the weight of active drug in all the formulations is less than $25 \mathrm{mg}$, therefore, content uniformity test has been performed to check the distribution of ADB. The results showed that all randomly selected tablets of each formulation have been prepared with uniformity in their content and the active drug is found to be within $\pm 15 \%$ limit (Table 4) indicating acceptable manufacturing process.

\section{Dissolution Studies}

The rate of drug absorption and its efficacy is related to the dissolution of the tablet. Therefore, it is important to estimate the amount of the drug that would be released from the tablet when placed in an environment of GIT37. There are many factors that can impact the rate at which a tablet disintegrates and the drug substance dissolves. These factors can be grouped into two broad categories, i.e. drug substance and drug product factors. For drug substance factors, salt form, polymorphic form, particle size, and surface area all play an important role in the dissolution of the drug. For drug product factors, the dissolution will be affected by the
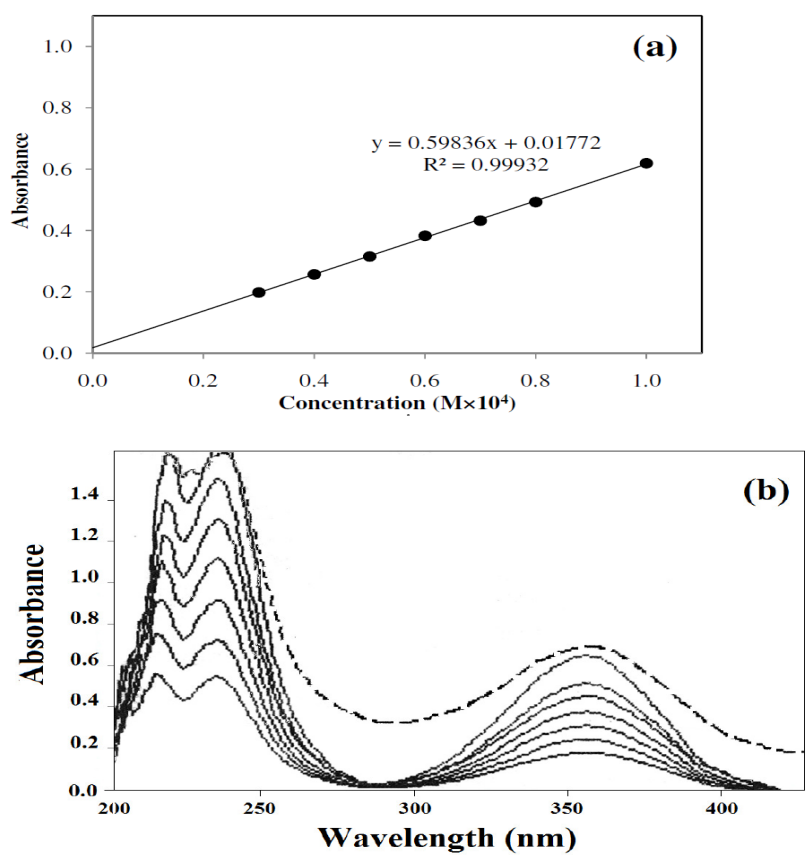

Figure 1: The calibration curve (a) and overlay spectra (b) of ADB. The dotted line in (b) indicates the spectrum of ADB in fast disintegrating tablets.

formulation process (granulation, etc.) and the excipients used. ${ }^{41}$

In this study, all fast disintegrating tablets showed a drug release of greater than $70 \%$ within 6 min (Table 7). On the contrary, at the same time, the conventional immediate release tablets of $\mathrm{ADB}$ showed a release of only $\sim 48 \%$ at the same time (Table 7 ). This indicates that the formulated fast disintegrating tablets are much more efficient in drug release as compared to the conventional release tablets of ADB (Figure 2). The amount of disintegrant present in the tablet has been found to play an important role in the release of the drug. 


\begin{tabular}{|c|c|c|c|c|c|c|c|c|}
\hline \multirow[b]{2}{*}{$\begin{array}{l}\text { Time } \\
\text { (min) }\end{array}$} & \multicolumn{8}{|c|}{ Cumulative drug release $(\%) \pm S D^{a}$} \\
\hline & $\begin{array}{c}\text { Commercial } \\
\text { Tablet }\end{array}$ & Standard & F1 & F2 & F3 & F4 & F5 & F6 \\
\hline 3 & $26.02 \pm 2.952$ & $47.05 \pm 4.777$ & $45.34 \pm 5.557$ & $47.62 \pm 3.676$ & $47.85 \pm 4.111$ & $44.45 \pm 4.604$ & $41.90 \pm 3.061$ & $51.10 \pm 2.564$ \\
\hline 6 & $47.68 \pm 5.913$ & $76.38 \pm 3.898$ & $74.39 \pm 3.569$ & $77.24 \pm 3.551$ & $75.58 \pm 3.726$ & $72.66 \pm 3.907$ & $70.54 \pm 3.087$ & $82.35 \pm 2.431$ \\
\hline 9 & $64.48 \pm 2.898$ & $85.48 \pm 5.107$ & $83.88 \pm 2.615$ & $86.44 \pm 4.244$ & $84.95 \pm 4.320$ & $82.54 \pm 4.648$ & $79.64 \pm 2.382$ & $90.50 \pm 2.176$ \\
\hline 12 & $76.66 \pm 1.354$ & $88.55 \pm 3.933$ & $87.41 \pm 2.822$ & $89.75 \pm 3.863$ & $88.78 \pm 4.542$ & $85.93 \pm 3.631$ & $83.44 \pm 1.875$ & $93.75 \pm 2.157$ \\
\hline 15 & $82.44 \pm 3.786$ & $90.14 \pm 3.599$ & $89.11 \pm 2.496$ & $91.45 \pm 3.234$ & $90.80 \pm 3.760$ & $87.65 \pm 3.575$ & $85.19 \pm 1.551$ & $95.35 \pm 1.675$ \\
\hline
\end{tabular}

a $n=6$ for each formulation.

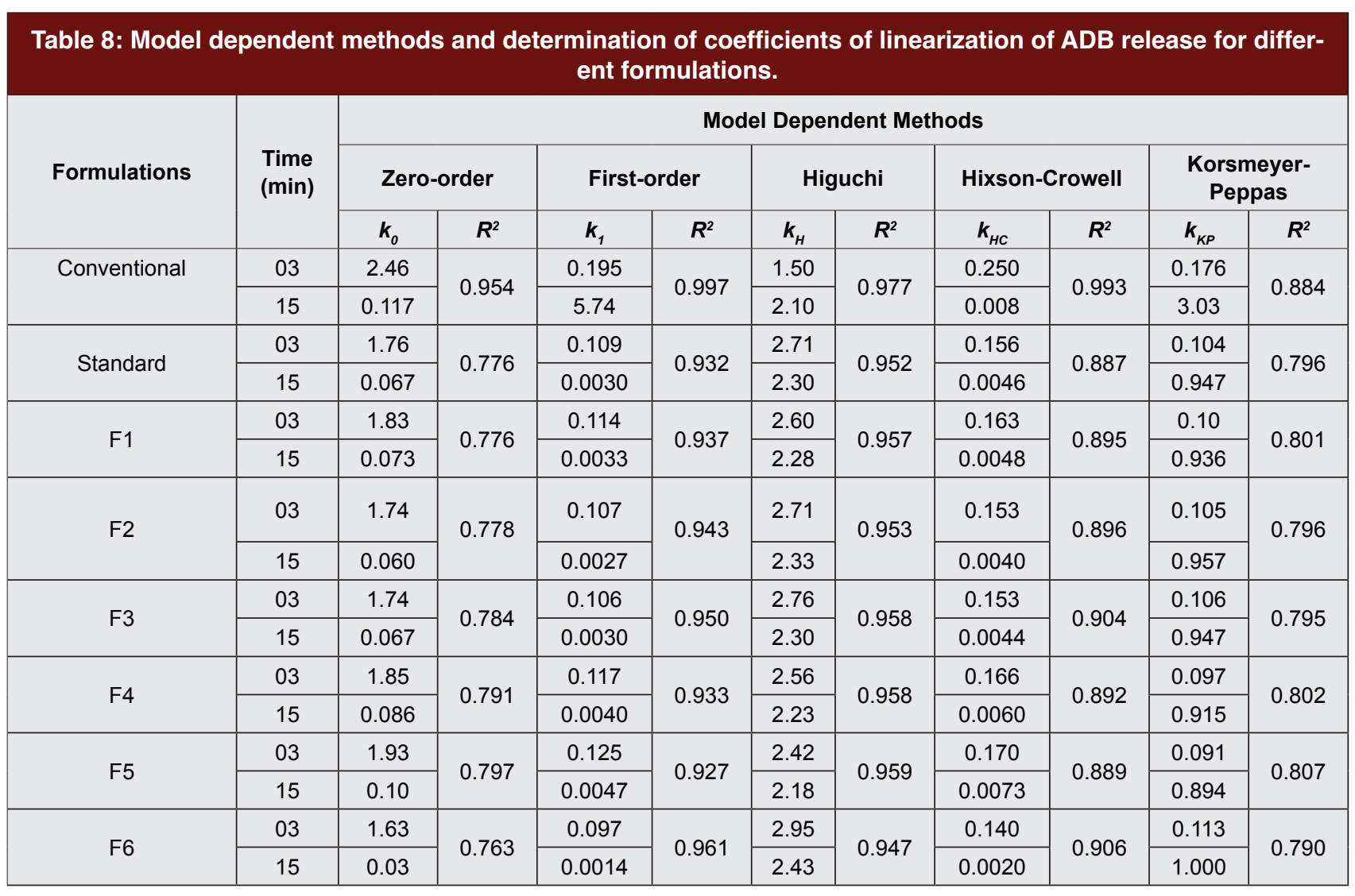

Among all the tablets, formulation 6 has been found to be the quickest and formulation 5 as the slowest in drug release as compared to other formulations, which is due to the highest and lowest amount of super disintegrant (sodium bicarbonate) present in these formulations, respectively (Table 2). Similar patterns of release with respect to the concentration of another disintegrant (sodium starch glycolate) and binder (povidone $\mathrm{K}-30$ ) have been observed in the remaining formulations but with less significant differences in the rate of release (Figure 2). Model-dependent release methods have been applied to the dissolution profile of the stan- dard and other prepared formulations (F1-F6) (Table 8). The results obtained from these models indicate that all formulations follow Higuchi model as the best fit. The regression values $\left(R^{2}\right)$ for all fast disintegrating formulations have been obtained in the range of 0.947 to 0.959 (Table 8). After Higuchi model, the second best fit model was found to be first-order where $R^{2}$ values are in the range of 0.927 to 0.961 (Table 8). In the case of conventional release tablets of $\mathrm{ADB}$, first-order model has been found to be the best fit for its release (Table 8). The similarity factor $\left(f_{2}\right)$ between the standard and other prepared formulations has also been calculated and is 
reported in Table 9. According to FDA, ${ }^{42,43}$ model-independent approach is better to compare the dissolution profile of different formulations of the same drug. The values obtained for the test tablets $(\mathrm{F} 1-\mathrm{F} 6)$ are compared with the standard formulation and the data interpretation has been made by a simple evaluation method. If the $f_{2}$ values are in the range of 50 to 100 , the dissolution profile for the test formulations is considered to be similar to the reference or standard formulation. ${ }^{32,33}$ All values are found to be greater than 50 and are in the range of 61.37-99.40 (Table 9), which indicates that the formulations prepared with varying excipient concentration have same dissolution profile as compared to that of the standard formulation. However, the $f_{2}$ values of F5 and F6 are found to be lower as compared to the others (F1-F4) which could be due to the different concentration of super-disintegrant (sodium bicarbonate) in the prepared formulations to those of the standard tablets (Table 2). On the contrary, the comparison of all seven test formulations with the conventional release tablets of $\mathrm{ADB}$ showed $f_{2}$ values of less than 50 indicat-

\begin{tabular}{|c|c|c|c|c|c|c|}
\hline \multirow{2}{*}{$\begin{array}{l}\text { Time } \\
(\min )\end{array}$} & \multicolumn{6}{|c|}{$f_{2}$ Value } \\
\hline & $\begin{array}{c}\text { Std } \\
\text { v/s F1 }\end{array}$ & $\begin{array}{l}\text { Std } \\
\text { v/s F2 }\end{array}$ & $\begin{array}{c}\text { Std } \\
\text { v/s F3 }\end{array}$ & $\begin{array}{l}\text { Std } \\
\text { v/s F4 }\end{array}$ & $\begin{array}{l}\text { Std } \\
\text { v/s F5 }\end{array}$ & $\begin{array}{c}\text { Std } \\
\text { v/s F6 }\end{array}$ \\
\hline 3 & 85.15 & 96.94 & 94.74 & 78.00 & 63.98 & 69.02 \\
\hline 6 & 82.61 & 93.91 & 94.54 & 70.70 & 64.38 & 60.92 \\
\hline 9 & 86.18 & 92.94 & 97.26 & 75.39 & 61.37 & 64.57 \\
\hline 12 & 91.01 & 90.29 & 99.40 & 77.62 & 64.18 & 63.80 \\
\hline 15 & 92.13 & 89.18 & 96.07 & 78.51 & 64.80 & 63.79 \\
\hline
\end{tabular}

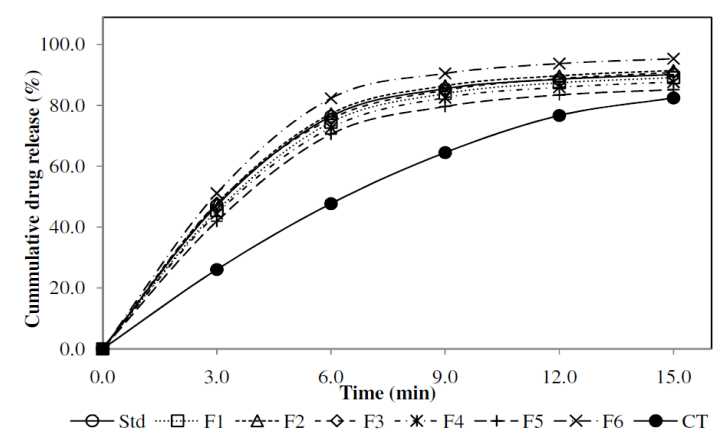

Figure 2: The release profile of ADB from fast disintegrating and conventional tablets (CT).

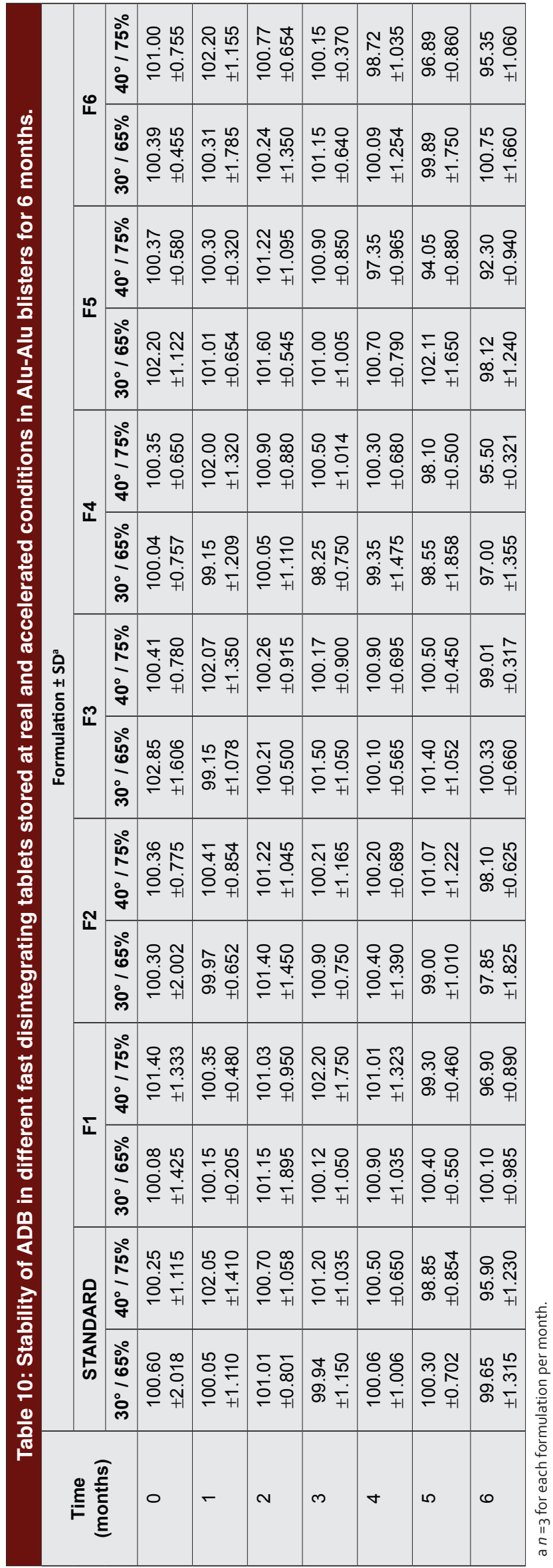


ing a significant difference between the releases of test and commercial tablets of ADB.

\section{Stability Studies}

Randomly, a number of tablets from each formulation packed in Alu-Alu blisters were selected and kept in the stability chamber at real time $\left(30 \pm 2^{\circ} \mathrm{C} / 65 \pm 5 \% \mathrm{RH}\right)$ and accelerated conditions $\left(40 \pm 2^{\circ} \mathrm{C} / 75 \pm 5 \% \mathrm{RH}\right)$. Prior to blistering, leakage test has been performed to make sure that the tablets are packed properly. Shelf-life of any dosage form is determined on the basis of $10 \%$ degradation of the active drug with respect to time. ${ }^{34}$

The assay data of the stability of ADB in fast disintegrating tablets indicated no concentration change in the standard as well as in formulations 1, 3 and 6 (Table 10). Around 2-3\% loss has been observed in formulations 2, 4 and 5 after six months of storage at $30^{\circ} \mathrm{C} / 65 \%$ $\mathrm{RH}$. This appears to be in the range of experimental error. Under accelerated conditions $\left(40^{\circ} \mathrm{C} / 75 \% \mathrm{RH}\right)$, all formulations including the standard showed a loss within $5 \%$. Thus, a change in temperature under the same humidity conditions appears to affect the drug that undergoes degradation to various levels within $5 \%$. This loss could be due to the effect of temperature on the drug in the presence of moisture which may involve some hydrolytic reaction ${ }^{44}$ in the molecule and/or an effect of excipients under these storage conditions. However, this loss can be considered within the permitted value of shelf life $\left(t_{90}\right)$ and the tablets are still acceptable for clinical use.

None of the tablets showed degradation of $10 \%$ or more at real and accelerated conditions after six months of storage (Table 8). The results indicated that all the fast disintegrating tablets of $\mathrm{ADB}$ are stable with the excipients of the formulations for a considerable period of time. Moreover, the Alu-Alu blisters are also found to be suitable for the packaging of fast disintegrating tablets of ADB.

\section{CONCLUSION}

The fast disintegrating tablets of ADB have been prepared by direct compression method. The study of pre and post compression parameters indicated a consistent manufacturing process that produced tablets with optimal physical characteristics. The excipients selected for the preparation of these tablets have shown an impact on the physicochemical characteristics of the formulations. All such effects are found to be concentration dependent; therefore, the use of optimum concentration of each excipient in the formulation is of highest consideration. The use of sodium bicarbonate as super disintegrant has greatly increased the disintegration and dissolution of the tablets resulting in the rapid release of the active drug. The binder has been shown to affect the tensile strength of the tablets. The stability studies at real and accelerated conditions for six months in aluminum blister packaging indicated no significant change in concentration in the majority of the formulations.

This study provides basic groundwork related to the formulation of fast disintegrating tablets of ADB. However, further work related to the bioavailability of ADB in such tablets would help in improving the formulation characteristics as well as its clinical efficacy. A detailed analysis of the degradation products formed during storage under normal and stressed conditions would also help in better understanding of the nature and mechanism of ADB degradation in the tablet dosage form and in the development of a formulation with optimum safety, stability and efficacy. Variations in the nature and content of excipients may further improve the physical and chemical characteristics of the tablets.

\section{ACKNOWLEDGEMENT}

The authors would like to acknowledge the kind support from the Board of Advanced Studies and Research (BASR), Baqai Medical University, Karachi.

\section{CONFLICT OF INTEREST}

The authors declare no conflict of interest.

\section{ABBREVIATIONS}

AD: Amlodipine; ADB: Amlodipine besylate; HR: Hausner ratio; ICH: International Council for Harmonization.

\section{REFERENCES}

1. Kottke MK, Rudnic EM. Tablet dosage forms. In: Banker GS, Rhodes CT (Eds.), Modern Pharmaceutics, $4^{\text {th }}$ ed., New York, USA: Marcel Dekker Inc. 2002;287-334.

2. Abdelbary G, Prinderre $P$, Eouani $C$, et al. The preparation of orally disintegrating tablets using a hydrophilic waxy binder. Int $\mathrm{J}$ Pharm. 2004;278(2):423-33.

3. Sarasjia S, Pandit V, Joshi HP. Preparation and evaluation of mouth dissolving tablets of salbutamol sulphate. Ind J Pharm Sci. 2007;69(3):467-9.

4. Raj BS, Punitha ISR, Dube S. Formulation and characterization of fast disintegrating tablets of amlodipine using superdisintegrants. J App Pharm Sci. 2012;2(8):118-23.

5. Radke RS, Jadhav JK, Chajeed MR. Formulation and evaluation of orodispersible tablets of baclofen. Int J Chem Tech Res. 2009;1(3):517-21.

6. Koizumi K, Watanabe $\mathrm{Y}$, Morita $\mathrm{K}$, et al. New method of preparing highporosity rapidly saliva soluble compressed tablet using mannitol with camphor: A subliming material. Int J Pharm. 1997;152(1):127-31.

7. Chandrasekhar R, Hassan Z, Al Husban F, et al. The role of formulation excipients in the development of lyophilised fast-disintegrating tablets. Eur $\mathrm{J}$ Pharm Biopharm. 2009;72(1):119-29. 
8. Kaushik D, Dureja H, Saini TR. Formulation and evaluation of olanzapine mouth dissolving tablets by effervescent. Indian Drugs. 2004;41:410-2.

9. Ford J. The current status of solid dispersion. Pharm Acta Helv. 1986;61(3):6988.

10. Dobetti L. Fast-melting tablets: Developments and technologies. Pharm Technol. 2001;12:44-50.

11. Sweetman SC. Martindale the complete drug reference, $36^{\text {th }}$ ed., London, UK: Pharmaceutical Press. 2009.

12. British National Formulary 73. London, UK: BMJ Group and Pharmaceutical Press. 2017.

13. Cutler SJ. Cardiovascular agents, In: Beale JM, Block JA, editors. Wilson and Gisvold's textbook of organic medicinal and pharmaceutical chemistry. $12^{\text {th }}$ ed., Baltimore, USA: Lippincott-Williams and Wilkins. 2011;626.

14. Moffat AC, Osselton MD, Widdop B. Clarke's analysis of drugs and poisons. $4^{\text {th }}$ ed. London, UK: Pharmaceutical Press. 2011.

15. Park JY, Kim KA, Lee GS, et al. Randomized, open-label, two-period crossover comparison of the pharmacokinetic and pharmacodynamic properties of two amlodipine formulations in healthy adult male Korean subjects. Clin Ther. 2004;26(5):715-23.

16. Lee HY, Kang HJ, Koo BK, et al. Clinic blood pressure responses to two amlodipine salt formulations, adipate and besylate, in adult korean patients with mild to moderate hypertension: a multicenter, randomized, double-blind, parallel-group, 8-week comparison. Clin Ther. 2005;27(6):728-39.

17. Sheraz MA, Ahsan SF, Khan MF, et al. Formulations of amlodipine: A review. J Pharm. 2016;2016:8961621.

18. ICH Harmonised Tripartite Guideline. Validation of Analytical Procedures: Text and Methodology Q2(R1). International Conference on Harmonization of Technical Requirements for Registration of Pharmaceuticals for Human Use, Geneva, Switzerland. 2005.

19. Narmada GY, Mohini K, Prakash RB, et al. Formulation, evaluation and optimization of fast dissolving tablets containing amlodipine besylate by sublimation method. Ars Pharm. 2009;50:129-44.

20. Bhardwaj V, Bansal M, Sharma PK. Formulation and evaluation of fast dissolving tablets of amlodipine besylate using different super disintegrants and camphor as sublimating agent. American-Eurasian J Sci Res. 2010;5(4):264-9.

21. Mohanachandran PS, Krishna MPR, Fels S, et al. Formulation and evaluation of mouth dispersible tablets of amlodipine besylate. Int $\mathrm{J}$ App Pharm. 2010;2(3):1-16.

22. Ghenge G, Pande SD, Ahmad A, et al. Development and characterisation of fast disintegrating tablet of amlodipine besylate using mucilage of Plantago ovata as a natural superdisintegrant. Int J Pharm Tech Res. 2011;3(2):938-45.

23. Shelke PV, Dumbare AS, Gadhave MV, et al. Formulation and evaluation of rapidly disintegrating film of amlodipine besylate. J Drug Deliv Ther. 2012;2(2):72-5.

24. Rowe RC, Sheskey PJ, Quinn ME. Handbook of pharmaceutical excipients, $6^{\text {th }}$ ed., London, UK. Pharmaceutical Press. 2009;129-33. 404-7.

25. FDA (US Food and Drug Administration). Inactive Ingredient Search. Available at: http://www.accessdata.fda.gov/scripts/cder/iig/index.Cfm, FDA/ Center for Drug Evaluation and Research, Office of Generic Drugs, Division of Labeling and Program Support. 2017.

26. British Pharmacopoeia. Monograph on Amlodipine besilate, Her Majesty's Stationary Office, London, UK. BMJ Group and Pharmaceutical Press. 2018.
27. Dahima R, Pachori A, Netam S. Formulation and evaluation of mouth dissolving tablet containing amlodipine besylate solid dispersion. Int $\mathrm{J}$ Chem Tech Res. 2010;2(1):706-15.

28. Yuksel N, Kanık AE, Baykara T. Comparison of in vitro dissolution profiles by ANOVA-based, model-dependent and-independent methods. Int J Pharm. 2000;209(1-2):57-67.

29. Costa P, Lobo JM. Modeling and comparison of dissolution profiles. Eur J Pharm Sci. 2001;13(2):123-33.

30. Dash S, Murthy PN, Nath L, et al. Kinetic modeling on drug release from controlled drug delivery systems. Acta Pol Pharm. 2010;67(3):217-23.

31. Khan F, Li M, Schlindwein W. Comparison of in vitro dissolution tests for commercially available aspirin tablets. Dissol Technol. 2013;2:48-58.

32. Gonjari ID, Karmarkar AB, Hosmani AH. Evaluation of in vitro dissolution profile comparison methods of sustained release tramadol hydrochloride liquisolid compact formulations with marketed sustained release tablets. Digest J Nanomater Biostruct. 2009;4:651-61.

33. Kvrns R, Sitta MH, Sarheed O, et al. Studies on the formulation and evaluation of fast dissolving dosage forms of loratadine. IAJPR. 2016;6:6631-47.

34. Sinko PJ. Martin's physical pharmacy and pharmaceutical sciences - Physical chemical and biopharmaceutical principles in the pharmaceutical sciences, $6^{\text {th }}$ ed., Baltimore, USA: Lippincott Williams and Wilkins. 2011;320:442-68.

35. Staniforth J. Powder flow. In: Aulton ME, editor. Pharmaceutics - the science of dosage form design, $2^{\text {nd }}$ ed., London, UK: Churchill Livingstone. 2002;197210.

36. Fiese EF, Hagen TA. Preformulation. In: Lachman L, Lieberman HA, Kanig JL. editors. The theory and practice of industrial pharmacy, Philadelphia, USA: Lea and Febiger, Harcourt Publishers. 1986;171-96.

37. Banker GS, Anderson NR. Tablets. In: Lachman L, Lieberman HA, Kanig JL, editors. The theory and practice of industrial pharmacy, Philadelphia, USA: Lea and Febiger, Harcourt Publishers. 1986;293-345.

38. United States Pharmacopeia 42 / National Formulary 37. Monograph on Amlodipine besylate. Rockville, MD: United States Pharmacopeial Convention, Inc. 2019.

39. Maswadeh HM, Al-Jarbou AN. An investigation on physical quality control parameters of dietary supplements tablets commercially available on the Kingdom of Saudi Arabia. Int J Appl Res Nat Prod. 2011;4(3):22-6.

40. Mattsson S, Nystrom C. Evaluation of critical binder properties affecting the compactibility of binary mixtures. Drug Dev Ind Pharm. 2001;27(30):181-94.

41. Bynum KC. Preformulation and early phase method development. In: Ahuja S, Seypinski S, editors, Handbook of modern pharmaceutical analysis, $2^{\text {nd }}$ ed., Amsterdam, The Netherlands: Elsevier Inc. 2011;361-96.

42. FDA (US Food and Drug Administration). Guidance for Industry: Dissolution Testing of Immediate Release Solid Oral Dosage Forms, Center for Drug Evaluation and Research, Rockville, MD, USA. 1997.

43. FDA (US Food and Drug Administration). Guidance for Industry: SUPAC-MR: Modified Release Solid Oral Dosage Forms - Scale-up and Postapproval Changes: Chemistry, Manufacturing and Controls; in vitro Dissolution Testing and in vivo Bioequivalence Documentation, Center for Drug Evaluation and Research, Rockville, MD, USA. 1997.

44. Saxena D, Damale S, Joshi A, et al. Forced degradation studies of amlodipine besylate and characterization of its major degradation products by LC-MS/ MS. Int J Life Sci Biotechnol Pharm Res. 2014;3(3):196-207. 


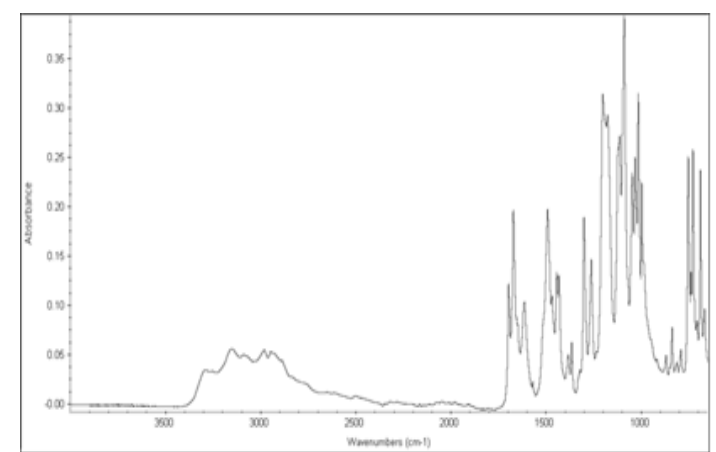

Supplementary Figure 1: FTIR spectrum of ADB.

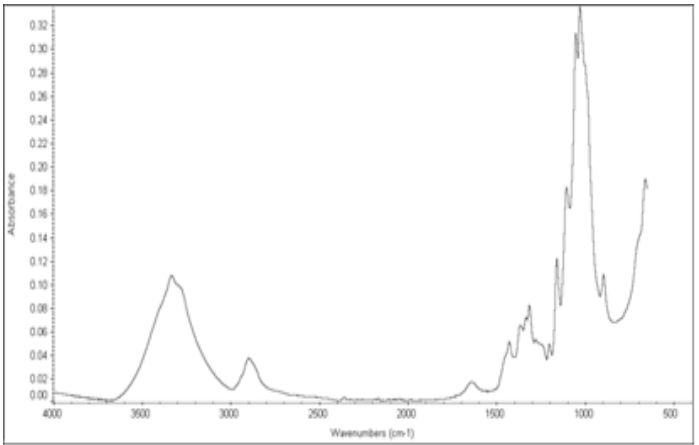

Supplementary Figure 2: FTIR spectrum of microcrystalline cellulose.

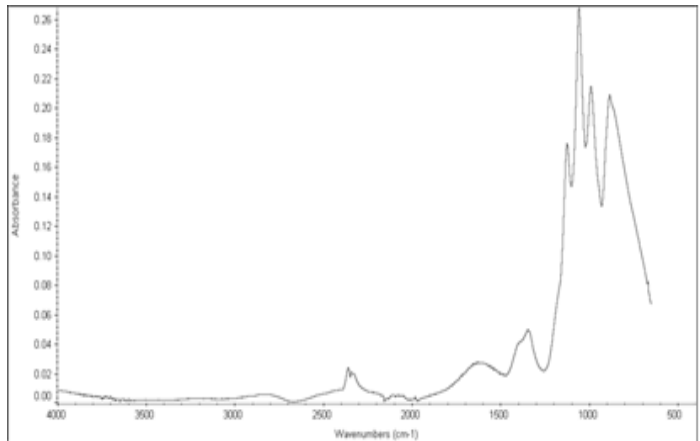

Supplementary Figure 3: FTIR spectrum of dibasic calcium phosphate anhydrous.

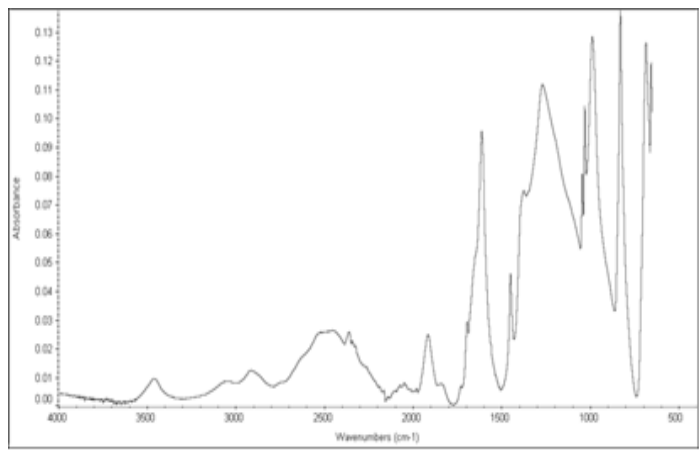

Supplementary Figure 4: FTIR spectrum of sodium bicarbonate.

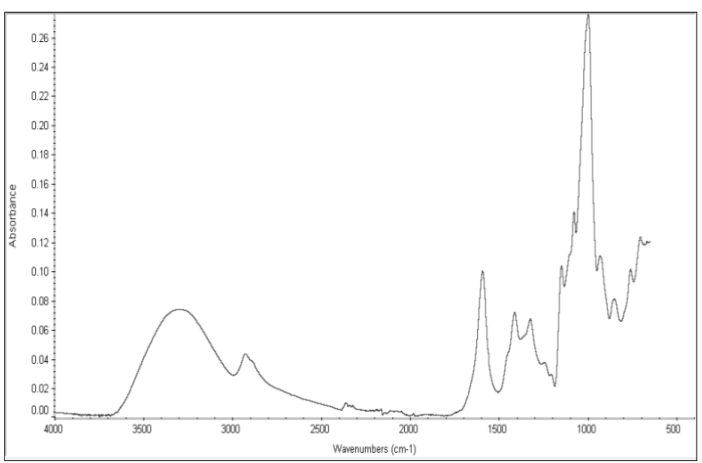

Supplementary Figure 5: FTIR spectrum of sodium starch glycolate

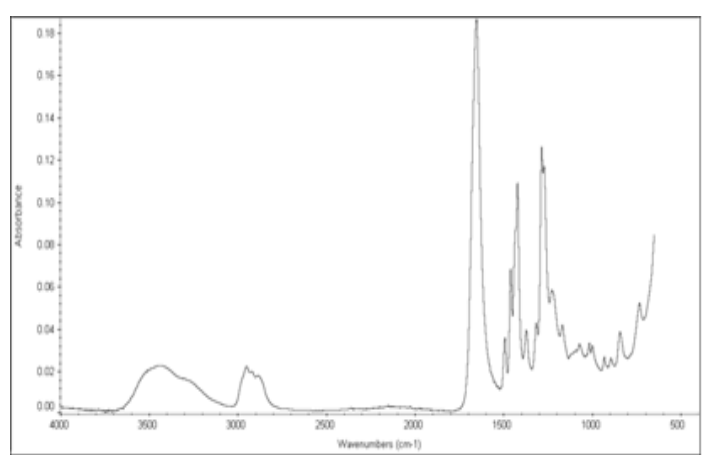

Supplementary Figure 6: FTIR spectrum of povidone K-30.

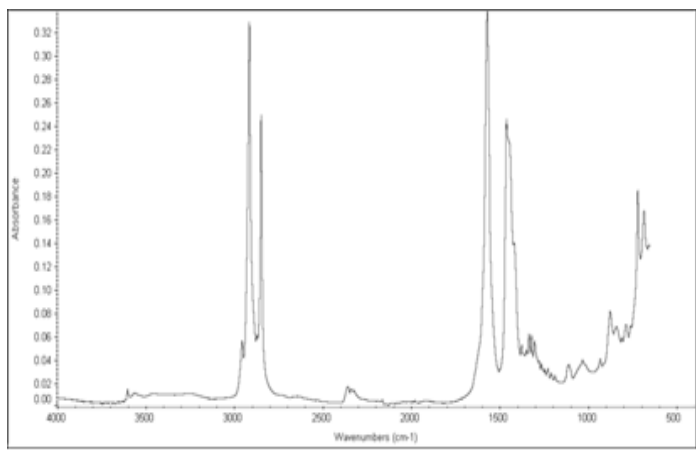

Supplementary Figure 7: FTIR spectrum of magnesium stearate. 
PICTORIAL ABSTRACT
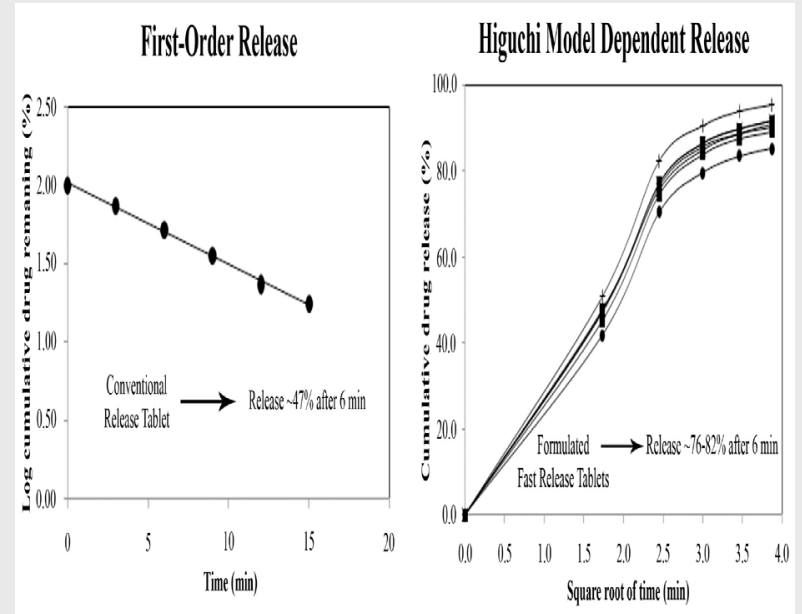

\section{ABOUT AUTHORS}

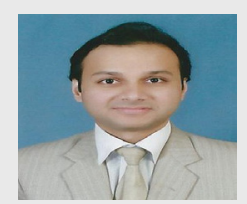

Dr. Muhammad Ali Sheraz is the Director of the Baqai Institute of Pharmaceutical Sciences and is also the Chairman of the Department of Pharmacy Practice at the Faculty of Pharmaceutical Sciences, Baqai Medical University, Karachi. He obtained Ph. D. degree in Pharmaceutics from Baqai Medical University and conducted Postdoctoral research at the University of Sheffield, UK on a fellowship awarded by Higher Education Commission of Pakistan. He is a HEC approved supervisor for M. Phil. and Ph. D. studies. He has published more than 90 research papers and has co-authored 12 chapters and 2 books. He has so far supervised 5 students for M. Phil. degree. He is also the Editor-in-Chief of the Baqai Journal of Health Sciences.

Cite this article: Ahsan SF, Sheraz MA, Khan MF, Anwar Z, Ahmed S, Ahmad I. Formulation and Stability Studies of Fast Disintegrating Tablets of Amlodipine Besylate. Indian J of Pharmaceutical Education and Research. $2019 ; 53(3): 480-93$. 